\title{
Dynamic Characterization during Gas Initial Desorption of Coal Particles and Its Influence on the Initiation of Coal and Gas Outbursts
}

\author{
Chaojie Wang ${ }^{1, *}$, Xiaowei Li ${ }^{2}$, Changhang Xu ${ }^{1}$, Yujia Chen ${ }^{2}$, Zexiang Tang ${ }^{1}$, Chao Zhang ${ }^{3}$, Yang Du ${ }^{1}$, \\ Xiangyang Gao ${ }^{4}$ and Chenglin Jiang ${ }^{2}$
}

Citation: Wang, C.; Li, X.; Xu, C.; Chen, Y.; Tang, Z.; Zhang, C.; Du, Y.; Gao, X.; Jiang, C. Dynamic

Characterization during Gas Initial Desorption of Coal Particles and Its Influence on the Initiation of Coal and Gas Outbursts. Processes 2021, 9, 1101. https://doi.org/10.3390/pr9071101

Academic Editor: Jin Bai

Received: 7 June 2021

Accepted: 22 June 2021

Published: 24 June 2021

Publisher's Note: MDPI stays neutral with regard to jurisdictional claims in published maps and institutional affiliations.

Copyright: (c) 2021 by the authors. Licensee MDPI, Basel, Switzerland. This article is an open access article distributed under the terms and conditions of the Creative Commons Attribution (CC BY) license (https:// creativecommons.org/licenses/by/ $4.0 /)$.
1 Department of Safety Science and Engineering, China University of Petroleum (East China), Qingdao 266580, China; changhangxu@upc.edu.cn (C.X.); Z20040118@s.upc.edu.cn (Z.T.); duyang@upc.edu.cn (Y.D.)

2 School of Safety Engineering, China University of Mining and Technology, Xuzhou 221116, China; ttgnhm@126.com (X.L.); Chenyj@cumt.edu.cn (Y.C.); c.j.wang921230@cumt.edu.cn (C.J.)

3 College of Safety Science and Engineering, Xi'an University of Science and Technology, Xi'an 710054, China; zc@xust.edu.cn

4 Xuehu Coal Mine, Henan Shenhuo Group Co., Ltd., Yongcheng 476600, China; B20040016@s.upc.edu.cn

* Correspondence: superj_wang@163.com; Tel.: +86-159-6555-9195

\begin{abstract}
The law of gas initial desorption from coals is greatly important for understanding the occurrence mechanism and predicting coal and gas outburst (hereinafter referred to as 'outburst'). However, dynamic characterization of gas initial desorption remains to be investigated. In this study, by monitoring the gas pressure and temperature of tectonically deformed (TD) coal and primary-undeformed (PU) coal, we established the evolution laws of gas key parameters during the initial desorption. The results indicate that the gas pressure drop rate, mass flow rate, initial desorption rate, and gas velocity increase with increasing gas pressure, with stronger gas dynamic effect, generating a high pressure gradient on the coal surface. Under the same gas pressure, the pressure gradient formed on the TD coal surface is greater than that formed on the surface of the PU coal, resulting in easily initiating an outburst in the TD coal. Moreover, the increased gas pressure increases temperature change rates (falling rate and rising rate) of coal mass. The minimum and final stable temperatures in the TD coal are generally lower compared to the PU coal. The releasing process of gas expansion energy can be divided into two stages exhibiting two peaks which increase as gas pressure increases. The two peak values for the TD coal both are about 2-3 times of those of the PU coal. In addition, the total gas expansion energy released by TD coal is far greater than that released by PU coal. The two peaks and the total values of gas expansion energy also prove that the damage of gas pressure to coal mass increases with the increased pressure, more likely producing pulverized coals and more prone to initiate an outburst.
\end{abstract}

Keywords: tectonically deformed coal; gas pressure gradient; temperature; gas dynamic disaster; coal and gas outburst; gas expansion energy

\section{Introduction}

The law of gas desorption in coal particles has always been the one breakthrough point to explore the issues of efficient coal-bed methane recovery and gas dynamic disaster prevention [1-5]. For the mechanism of gas dynamic disasters such as outburst, as an outburst process only takes a few $\sim$ tens of seconds with an average time of $20 \mathrm{~s}$ [6], the law of gas initial desorption in coal particles is a key point that needs to be explored. When an outburst occurs, dozens of people are killed together along with the destruction of many coal mining facilities. After more than 180 years of research, the outburst mechanism still needs further investigation [7]. The main applied force for the occurrence of an outburst is the in situ stress under the mine leading to the initial failure of coal mass, while the 
gas pressure is the main force for the continuous damage of coal mass until the initiation of an outburst. From the perspective of energy release, gas energy is the main energy provider for an outburst occurrence, and the gas expansion energy leads to an outburst development $[8,9]$. Therefore, revealing the evolution law of gas parameters in the initial desorption process of coal particles and further obtaining the release law of gas expansion energy can contribute to revealing dynamic characterization of gas desorption improving understanding of an outburst occurrence mechanism.

At present, more attention has been paid to the evolution characterization of desorption rate and capacity and the establishment of theoretical models in the gas initial desorption process of coal particles [3,4,10-15]. In the view of the fact that the outbursts mainly occur in the TD coal with low mechanical strength, the research shows that the capacity of gas desorption of the TD coal is better than the PU coal [16]. The reasons for their differences have been clearly explained from the microstructures of coals after a detailed literature review [17-21]. The gas initial desorption law of the TD coal conforms to the Venter formula, while the law of the PU coal can be expressed by the Barrel formula or Venter formula [22,23]. It is difficult to collect the gas initial desorption amount when determining the gas desorption index of outburst prediction on site and is often estimated according to the above theoretical formulas [5]. Although the research results have certain practical significance for outburst prediction, the understanding of the outburst occurrence mechanism is still insufficient. At the micro-level, the gas desorption process in coal particles is a type of gas diffusion movement in porous media [24]; at the macro-level, it is a complex dynamic behavior accompanied by the change of gas pressure, temperature, desorption rate, gas velocity, and other variables. These parameters are directly related to the dynamic effect of gas desorption. On the one hand, the mechanical strength of coal mass is weakened by the gas embedded in the coal mass. On the other hand, as the gas pressure increases, the stress intensity factor generated at the crack discontinuity in the coal mass during desorption increases, and the easier the crack is to propagate, tear the coal mass, and induce an outburst $[25,26]$. The process of gas adsorption-desorption in coals is an energy exchange process [26-29]. During the desorption process, the temperature change of the coal mass corresponds to the exchange of heat energy on the coal surface and also reflects the gas release capacity to a certain extent [30]. The research results have shown that when the gas is desorbing, the temperature of the coal particles decreases rapidly and then increases gradually. The gas desorption capacity and the temperature drop increase with the increased coal rank and gas pressure for the TD coal [12]. Based on this remarkable change in temperature, the outburst risk can also be effectively predicted by using the measured temperature value of coal cuttings [31]. An outburst occurrence is an energy evolution process. A clear understanding of the gas energy release characterization of gas initial desorption from coals can better reveal the outburst occurrence mechanism and improve the accuracy of outburst risk prediction. Studies have shown obvious differences in the quantitative characterization of cumulative initial energy, especially cumulative initial expansion energy of gas, between the PU and TD coals and are closely related to the outburst risk $[7,20,32,33]$. In order to more accurately obtain the cumulative gas initial expansion energy released by coals and the corresponding risk prediction critical value of outburst of coal mass, correlation analysis was also conducted for various affecting factors such as gas types, moisture, gas pressure, nozzle area, coal particle size, and coal rank, of the cumulative initial released gas expansion energy [32-36]. However, the evolution law of key parameters such as gas pressure, temperature, mass flow rate, and gas velocity in the gas initial desorption process has been rarely studied, especially the pressure and velocity of gas; meanwhile, the dynamic characterization of the gas initial desorption has yet to be reported. In addition, gas pressure is one of the main factors of an outburst occurrence, and the current understanding of the effect of gas pressure on the outburst occurrence mechanism mainly stays in the research of coal failure modes and gas desorption law. The outburst occurrence mechanism can be mainly understood by investigating the release 
law of gas expansion energy generated by gas pressure; however, it has been scarcely investigated.

A self-assembled gas initial adsorption-desorption device of coal sample was used to collect the gas pressure and temperature change data synchronous with gas desorption process hereof. Based on the aerodynamic theory, the evolution laws of initial desorption and released expansion energy of gas of TD coal and PU coal were compared and analyzed. The research results aim to further improve the understanding of the effect of coal properties and gas pressure on outburst occurrence mechanism through the evolution law of gas pressure, temperature, mass flow rate, and gas velocity to improve the understanding of an outburst occurrence process.

\section{Experimental}

\subsection{Coal Sample}

The tested coal samples were selected from the TD coal with a high outburst risk and PU coal without an outburst risk from China's Xuehu coal mine, and the coal ranks of both coals were anthracite. At $200 \mathrm{~m}$ away from the coal sample collection site, an outburst accident occurred on 15 May 2017, with a coal ejection quantity of $164 t$, resulting in the death of three people. The coal sample was sealed at the collection site and taken to the laboratory. For both coal samples, the protodyakonov coefficients $(f$ value) are 0.28 (TD coal) and 0.88 (PU coal); the maximum adsorption capacities are $30.53 \mathrm{~m}^{3} / \mathrm{t}$ (TD coal) and $26.22 \mathrm{~m}^{3} / \mathrm{t}$ (PU coal); the moisture is 1.31\% (TD coal) and 1.06\% (PU coal); and the apparent densities are $1.44 \mathrm{~cm}^{3} / \mathrm{g}$ (TD coal) and $1.45 \mathrm{~cm}^{3} / \mathrm{g}$ (PU coal). The pore size distributions of the two coal samples are shown in the Table 1.

Table 1. Pore size distribution of coal sample.

\begin{tabular}{|c|c|c|c|c|c|c|c|c|c|c|c|}
\hline \multirow{2}{*}{$\begin{array}{c}\text { Coal } \\
\text { Sample }\end{array}$} & \multirow{2}{*}{ Item } & \multicolumn{2}{|c|}{ Macropore (>1000 nm) } & \multicolumn{2}{|c|}{$\begin{array}{c}\text { Mesopore } \\
(100-1000 \mathrm{~nm})\end{array}$} & \multicolumn{2}{|c|}{$\begin{array}{c}\text { Ascopore } \\
(\mathbf{1 0 - 1 0 0 ~ n m )}\end{array}$} & \multicolumn{2}{|c|}{ Micropore $(<10 \mathrm{~nm})$} & \multicolumn{2}{|c|}{ In Total } \\
\hline & & $\mathrm{V}(\mathrm{mL} / \mathrm{g})$ & $\mathrm{S}\left(\mathrm{m}^{2} / \mathrm{g}\right)$ & $\mathrm{V}(\mathrm{mL} / \mathrm{g})$ & $\mathrm{S}\left(\mathrm{m}^{2} / \mathrm{g}\right)$ & $\mathrm{V}(\mathrm{mL} / \mathrm{g})$ & $\mathrm{S}\left(\mathrm{m}^{2} / \mathrm{g}\right)$ & $\mathrm{V}(\mathrm{mL} / \mathrm{g})$ & $\mathrm{S}\left(\mathrm{m}^{2} / \mathrm{g}\right)$ & $\mathrm{V}(\mathrm{mL} / \mathrm{g})$ & $\mathrm{S}\left(\mathrm{m}^{2} / \mathrm{g}\right)$ \\
\hline \multirow{2}{*}{ TD coal } & Value & 0.0323 & 0.213 & 0.0163 & 1.080 & 0.0126 & 9.025 & 0.0109 & 13.151 & 0.0721 & 23.469 \\
\hline & Ratio (\%) & 44.80 & 0.91 & 22.61 & 4.60 & 17.47 & 38.46 & 15.12 & 56.03 & 100 & 100 \\
\hline \multirow{2}{*}{ PU coal } & Value & 0.0059 & 0.409 & 0.0055 & 0.950 & 0.0084 & 6.025 & 0.015 & 9.108 & 0.0348 & 16.492 \\
\hline & Ratio (\%) & 16.82 & 2.48 & 15.82 & 5.76 & 24.17 & 36.54 & 43.19 & 55.23 & 100 & 100 \\
\hline
\end{tabular}

\subsection{Experimental Principle and Device}

Previous studies mainly focused on the direct measurement of the volume of the gas released at different times to investigate the gas initial desorption law of coal particles $[5,19,23]$. Although the gas initial desorption data of tens of seconds can still be obtained by means of a high-speed camera, the gas involved in the outburst development has an actual pressure effect and can result in instantaneous pressure difference to destroy coals. Conventional monitoring methods cannot obtain the change of gas pressure of initial process; therefore, it is difficult to distinguish the gas with pressure effect. Based on the theory of aerodynamics, temperature sensor, and two pressure sensors with different ranges (one works in the range of about 1-2 MPa and the other one works in the range of $0-3 \mathrm{KPa}$, which is activated when the pressure is less than $3000 \mathrm{~Pa}$ ) were selected to collect the temperature and gas pressure data of gas desorption. The specific test device is shown in Figure 1.

The time interval of data acquisition is approximately1.6 ms, and a total of 8000 times are collected, i.e., the change in gas pressure and temperature is recorded about first $13 \mathrm{~s}$. Then, according to the principle of aerodynamics, the rate of mass flow, the velocity of gas and the gas expansion energy can be obtained by calculation (see Figure 2). The size range of the coal sample used in the test is 1-3 $\mathrm{mm}$ (the coals with this particle size are commonly used in outburst prediction index determination in China). The two coal samples are prepared into 4 groups respectively, and the quality of each group sample is $\sim 200 \mathrm{~g}$. The equilibrium pressures of the gas adsorption of coal samples include four levels (TD coal 
(MPa): 0.409, 0.606, 0.801, and 0.992; PU coal (MPa): 0.409, 0.609, 0.797, and 0.998). The specific test processes are shown below.

(1) A coal sample ( $200 \mathrm{~g}$ ) was put into the sample tank (' $\left.{ }^{\prime}\right)$ and the vacuuming time is not less than $8 \mathrm{~h}$. Then, the gas charging for the coals in the thermostatic bath ('10') lasted for at least $12 \mathrm{~h}$ until the equilibrium pressure was stable.

(2) The data acquisition system (' 1 ') was turned on to acquire the gas pressure and temperature data after stopping the gas charging. Then, the tapered nozzle (' 6 ') was quickly opened.

(3) Because the void volume without coals in sample tank influences the test result, steel balls with the same bulk volume of the coal sample were placed into the sample tank to acquire the temperature and gas pressure data given in Steps 1 and 2 under the same equilibrium pressure with the coals.

(4) Finally, the obtained gas pressure and temperature data were used to obtain the data of mass flow rate, gas velocity, and gas expansion energy based on the equations in Figure 2.

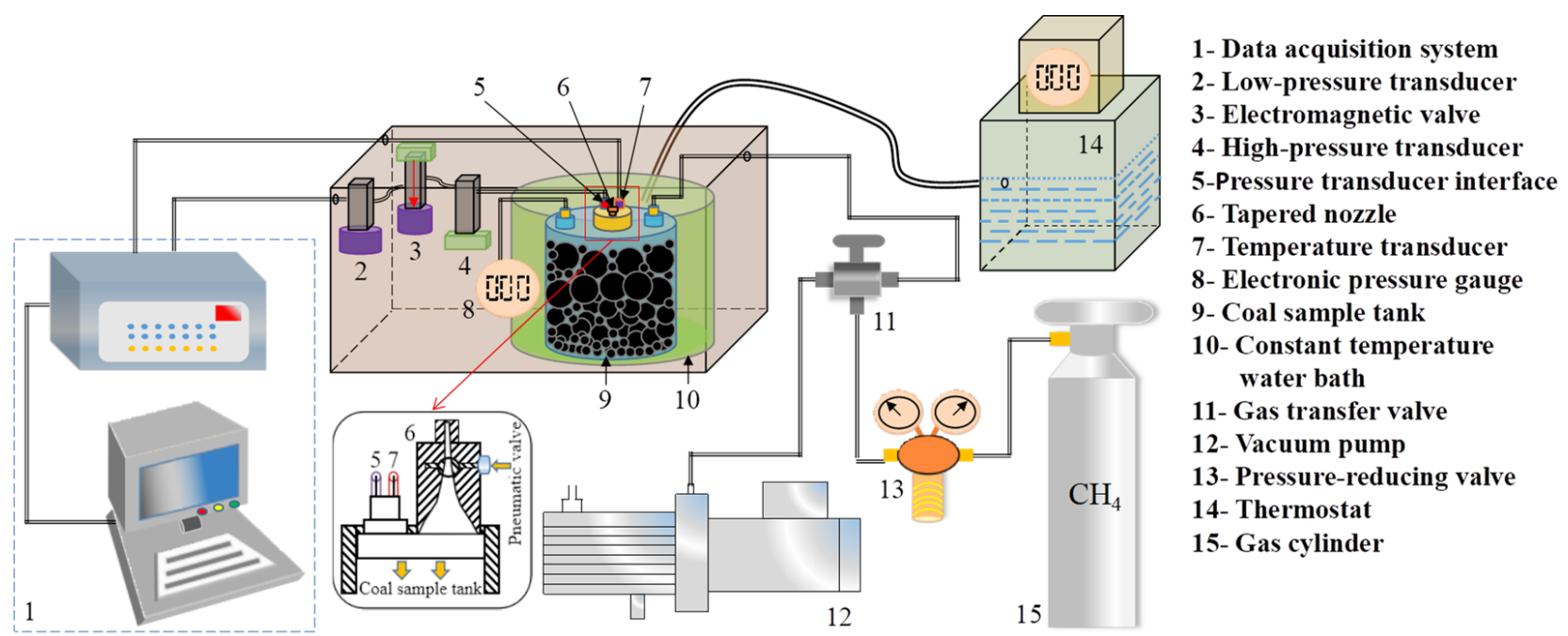

Figure 1. Schematic diagram of the test device.

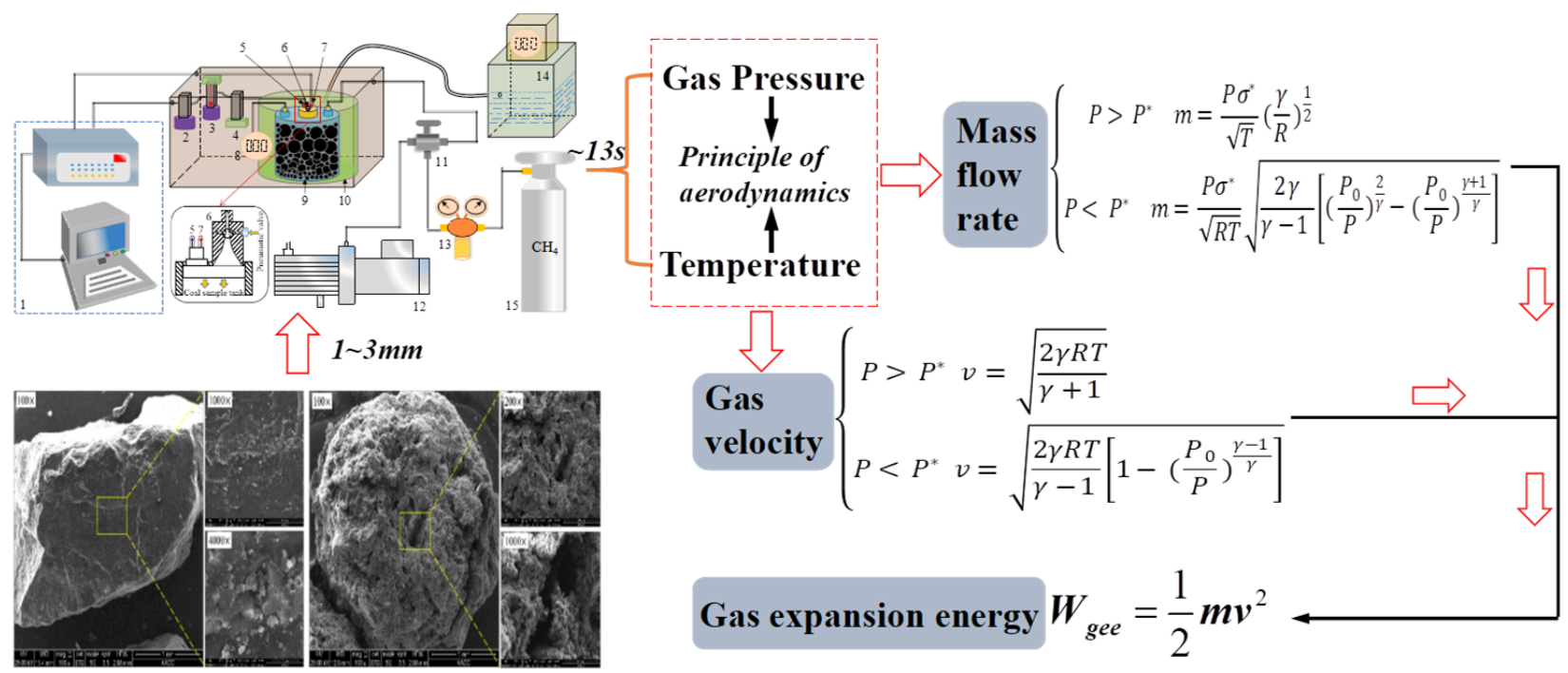

Figure 2. The flow of data processing. 


\section{Results}

\subsection{The Change of Gas Pressure}

Figure 3 shows the collected gas pressure data of coal sample during the gas initial desorption, indicating that the increased gas pressure increases the time taken for the pressure to drop to the minimum value. However, the period of pressure drop of TD coal lasts significantly longer. In order to build the gas diffusion model for coal particles, $\mathrm{Xu}$ et al. [11] deduced the evolution relationship of change of gas pressure with time, conforming to the exponential function through desorption experiments. Based on this, the evolution process of gas pressure in the entire gas initial desorption was fitted by exponential function. The fitting results are listed in Table 2. According to the fitting correlation degree $\left(R^{2}\right)$ in the table, the change in the gas pressure with time satisfies the exponential function, and with increasing gas pressure, the degree of correlation is slightly higher. In addition, according to the first derivative $\left(\mathrm{P}^{\prime}\right)$ of the fitting function, when the gas pressure increases, the pressure drop rate increases. In addition, for both coals, the gas pressure drops faster in the PU coal. The destructive nature of the gas pressure when an outburst initiates is reflected by the pressure gradient near the exposed coal surface $[37,38]$. During the process, the low gas pressure drop rate produces the high pressure gradient and then induces the strong damage to the coal mass [39]. The fitting formula in Table 2 shows that during the initial desorption of TD coal, the gas pressure drops at a slower rate than that of the PU coal, and greater gas pressure gradient near the surface of the TD coal leads the outburst to occur more easily.

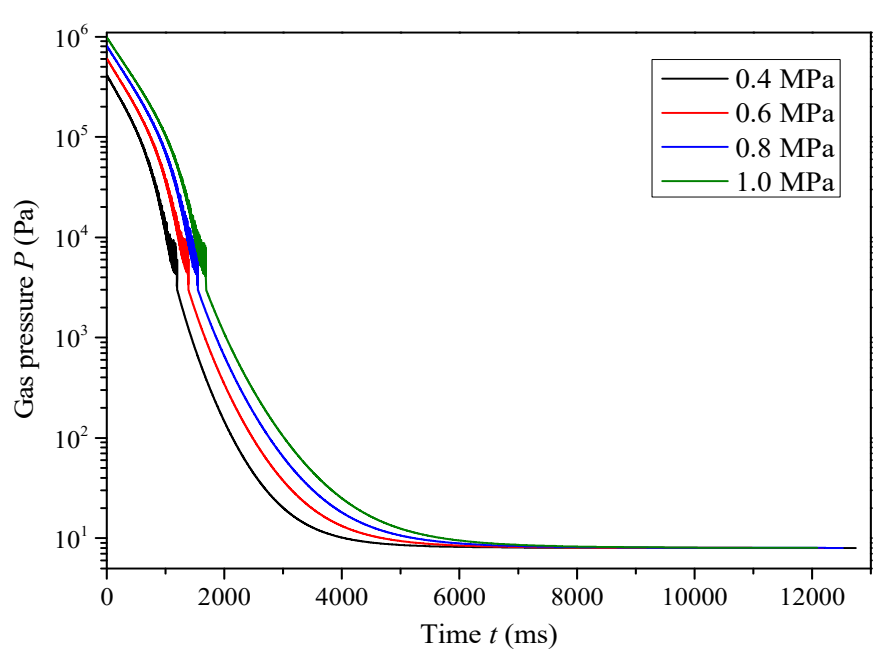

(a) TD coal

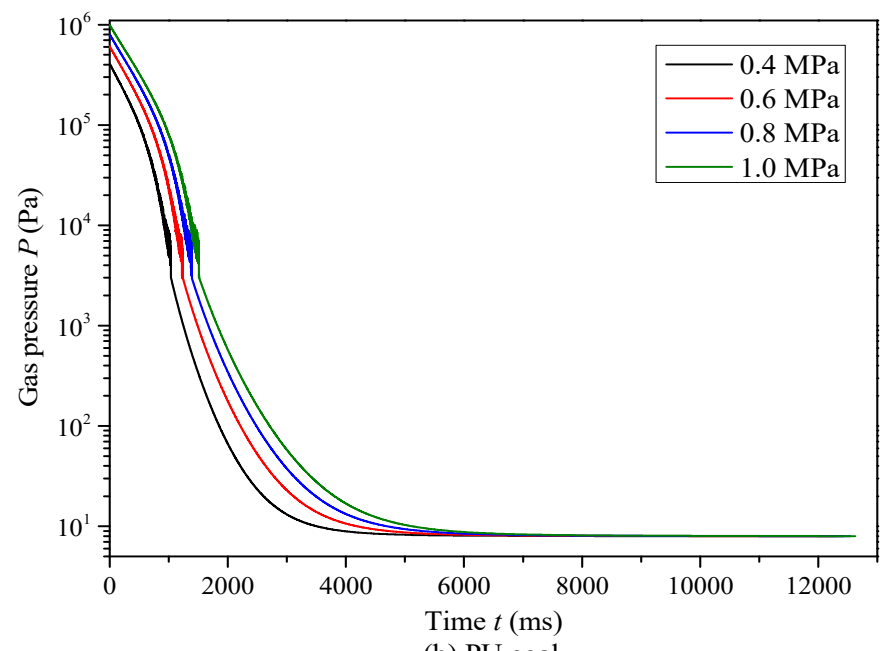

(b) PU coal

Figure 3. Change curve of gas pressure with time during gas initial desorption of coal particles.

Table 2. Fitting relationship of gas pressure vs. time during the initial desorption.

\begin{tabular}{|c|c|c|c|c|}
\hline Coal Sample & $\begin{array}{c}\text { Gas Pressure P } \\
(\mathrm{MPa})\end{array}$ & Fitted Equation & First Derivative $\mathbf{P}^{\prime}$ & $\begin{array}{c}\text { Degree of } \\
\text { Correlationr }\end{array}$ \\
\hline \multirow{4}{*}{ TD coal } & 0.409 & $P=-659.496+436,292 e^{-t / 359.712}$ & $\mathrm{P}^{\prime}=-1212.893 \mathrm{e}^{-\mathrm{t} / 359.712}$ & 0.99496 \\
\hline & 0.606 & $\mathrm{P}=-1073.261+630,350 \mathrm{e}^{-\mathrm{t} / 403.226}$ & $\mathrm{P}^{\prime}=-1563.267 \mathrm{e}^{-\mathrm{t} / 403.226}$ & 0.99608 \\
\hline & 0.801 & $\mathrm{P}=1389.513+836,487.8 \mathrm{e}^{-\mathrm{t} / 431.034}$ & $\mathrm{P}^{\prime}=-1940.652 \mathrm{e}^{-\mathrm{t} / 431.034}$ & 0.99692 \\
\hline & 0.992 & $\mathrm{P}=-1753.92+1,012,430 \mathrm{e}^{-\mathrm{t} / 454.545}$ & $\mathrm{P}^{\prime}=-2227.348 \mathrm{e}^{-\mathrm{t} / 454.545}$ & 0.99745 \\
\hline \multirow{4}{*}{ PU coal } & 0.409 & $\mathrm{P}=-639.433+431,328.422 \mathrm{e}^{-\mathrm{t} / 330.033}$ & $\mathrm{P}^{\prime}=-1306.925 \mathrm{e}^{-\mathrm{t} / 330.033}$ & 0.99451 \\
\hline & 0.609 & $P=-1013.559+635,038.221 \mathrm{e}^{-\mathrm{t} / 371.747}$ & $\mathrm{P}^{\prime}=-1708.254 \mathrm{e}^{-\mathrm{t} / 371.747}$ & 0.99578 \\
\hline & 0.797 & $\mathrm{P}=-1301.629+827,524.72 \mathrm{e}^{-\mathrm{t} / 398.406}$ & $\mathrm{P}^{\prime}=-2077.089 \mathrm{e}^{-\mathrm{t} / 398.406}$ & 0.99666 \\
\hline & 0.998 & $P=-1582.278+1,019,830 e^{-t / 420.168}$ & $\mathrm{P}^{\prime}=-2427.196 \mathrm{e}^{-\mathrm{t} / 420.168}$ & 0.99727 \\
\hline
\end{tabular}




\subsection{Temperature Change}

The time-variation law of temperature during the gas initial desorption is presented in Figure 4, indicating that with increasing gas desorption time, the temperature of coal mass first decreases rapidly (Stage 1), then rises rapidly (Stage 2), and finally tends to be stable (Stage 3). The final temperature value after the stabilization is less than the initial equilibrium temperature value. This change law of temperature indicates that during the gas initial desorption, the free gas in the coal mass is released first, because of sudden release of gas pressure at the beginning, and the adsorbed gas rapidly desorbs with decreasing gas concentration in the gas seepage channel. The process of gas separation from the coal mass needs energy consumption, decreasing the coal mass temperature. Figure 4 shows that the temperature of the coal mass drops rapidly in Stage 1, indicating that the heat consumed by the gas desorption is more than that of the external heat transfer in this process. In Stage 2, the coal temperature rises rapidly with the gas desorption, and in Stage 3, the coal temperature finally tends to be stable. This shows that in this process, because of decreasing gas desorption amount, the heat consumption of the gas desorption is less than that of the external heat transfer. However, the heat consumed by the gas desorption in Stage 1 cannot be completely supplemented in the whole process of gas initial desorption. Therefore, the final desorption temperature is still lower than the initial temperature. At the same time, the figure shows that the increased gas pressure produces the faster temperature change rate (falling rate and rising rate). Figure 5 shows the fitting functions between the temperature and gas pressure of the coals, indicating that the increased gas pressure reduces the minimum and final stable temperatures of the coal particles; for TD coal, the minimum and final stable temperatures of coals are lower generally. The minimum and the final stable temperature values of the coals are linearly related to gas pressure shown in Figure 5, and the temperature of the coal mass changes significantly and regularly, making many scholars think that the change in coal mass temperature can be used as an index to predict the outburst risk [31].

\subsection{Mass Flow Rate Change}

According to the principle of aerodynamics in the Figure 2, Figure 6 shows the change curve of rate of mass flow with time during the gas initial desorption, indicating that with increasing gas pressure, the mass flow rate increases, requiring more time from rapid drop stage to stable stage. When bearing the same gas pressure, the rate of gas mass flow of the TD coal is greater compared with the PU coal at different times. Moreover, the time required for the TD coal from the rapid drop stage to stable stage is longer compared with the PU coal. The desorption rate of gas from the coals at the initial time has always been a key parameter in the gas desorption volume calculation and outburst risk prediction of coals. The correlation of the gas desorption rate with gas pressure is shown in Figure 7, indicating that under different gas pressures, the rate of mass flow of gas desorption of the TD coal at the initial time is approximately twice as much as that of the PU coal. The results have shown that the correlation of the gas desorption rate with gas pressure at the initial time conforms to the power function [23]. According to Figure 7, the correlation of the mass flow rate and gas pressure at the initial desorption time also has a linear correlation trend. Figure 7 also shows the fitting formula of the mass flow rate with gas pressure at the initial time. The correlation degree of different fitting methods shown in the figure indicates that the correlation of the mass flow rate with gas pressure at the initial time of TD coal can be expressed by power function or linear function, while that of the PU coal can be better expressed by linear function. In addition, whether it is a power function or a linear function, the gas pressure has a greater effect on the mass flow rate at the initial time of the TD coal. 


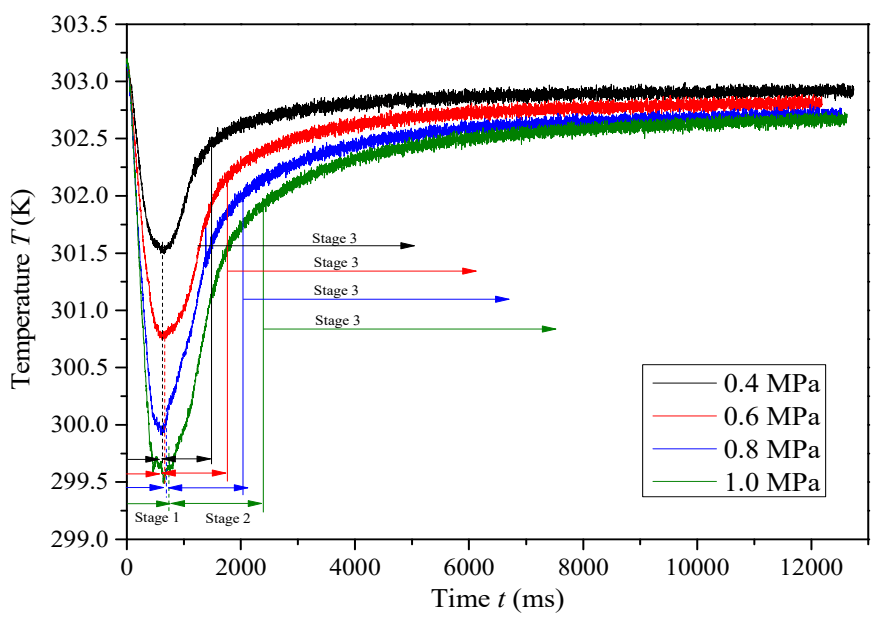

(a) TD coal

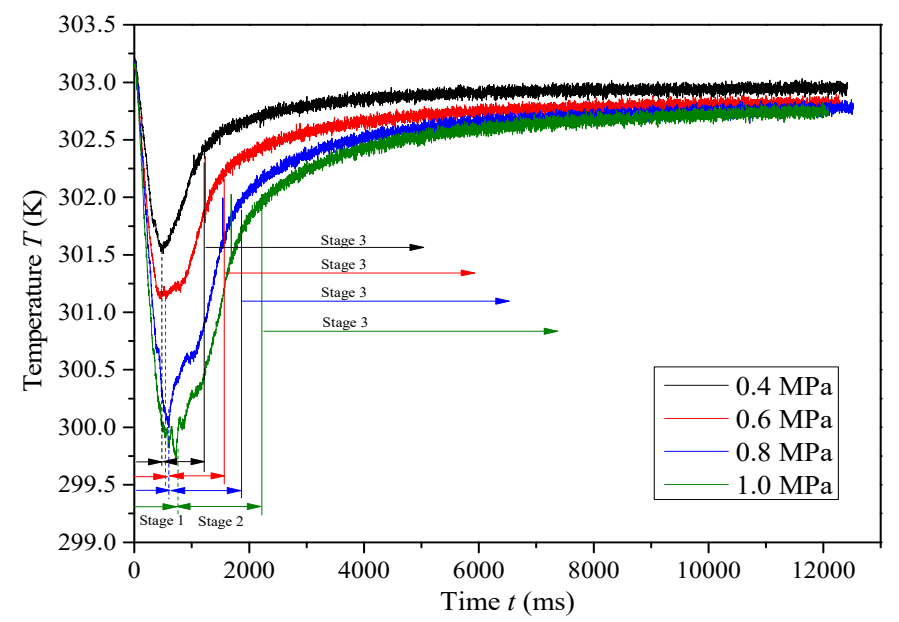

(b) PU coal

Figure 4. Change curve of temperature with time during the gas initial desorption of coal particles.

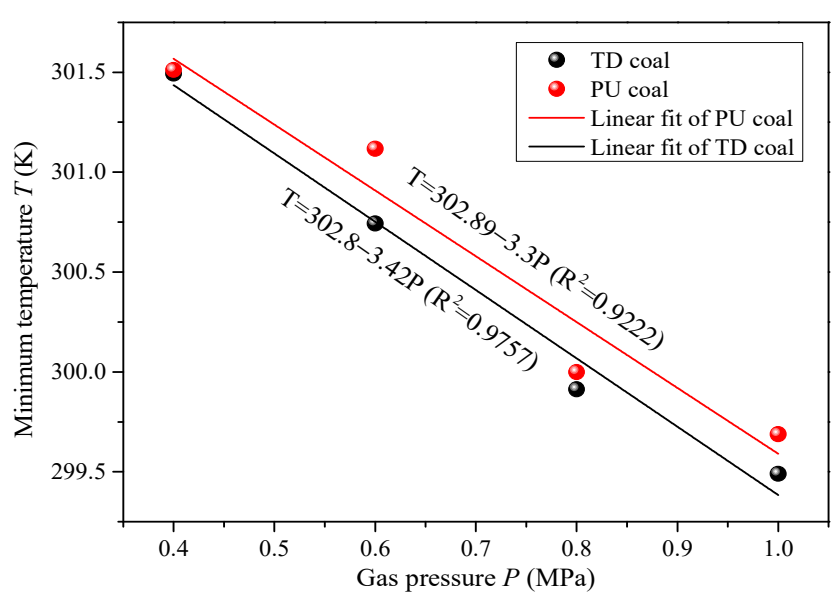

(a) Minimum temperature of coal sample during gas desorption

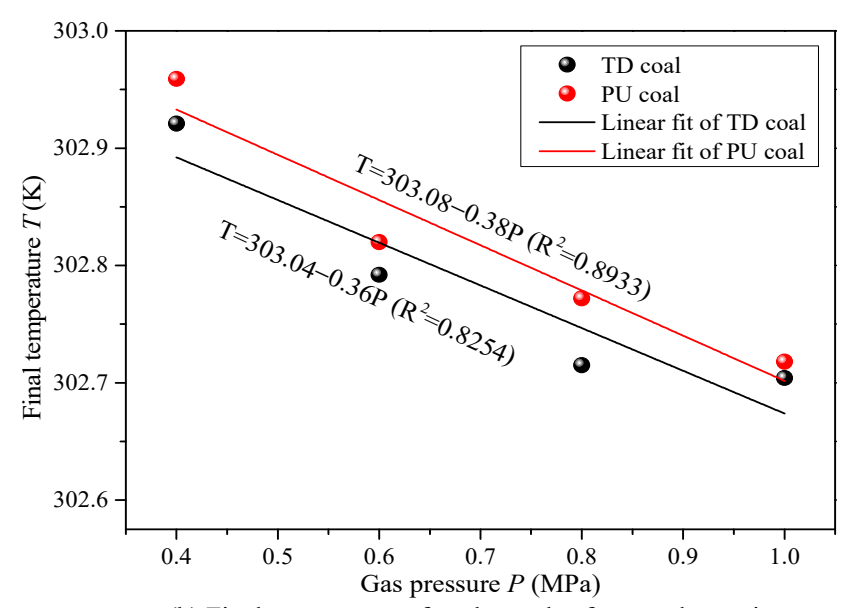

(b) Final temperature of coal sample after gas dersoption

Figure 5. Relationship of the temperature vs. gas pressure.
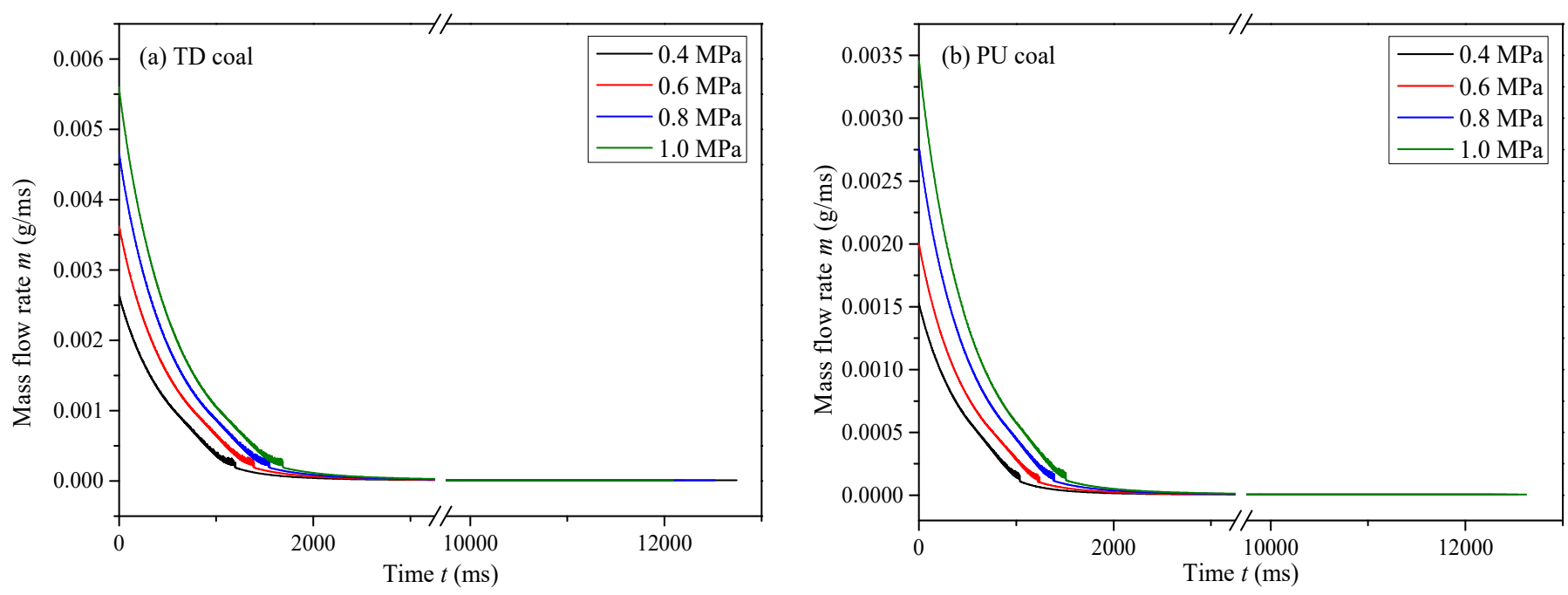

Figure 6. Change curve of mass flow rate vs. time during gas initial desorption of coal particles. 


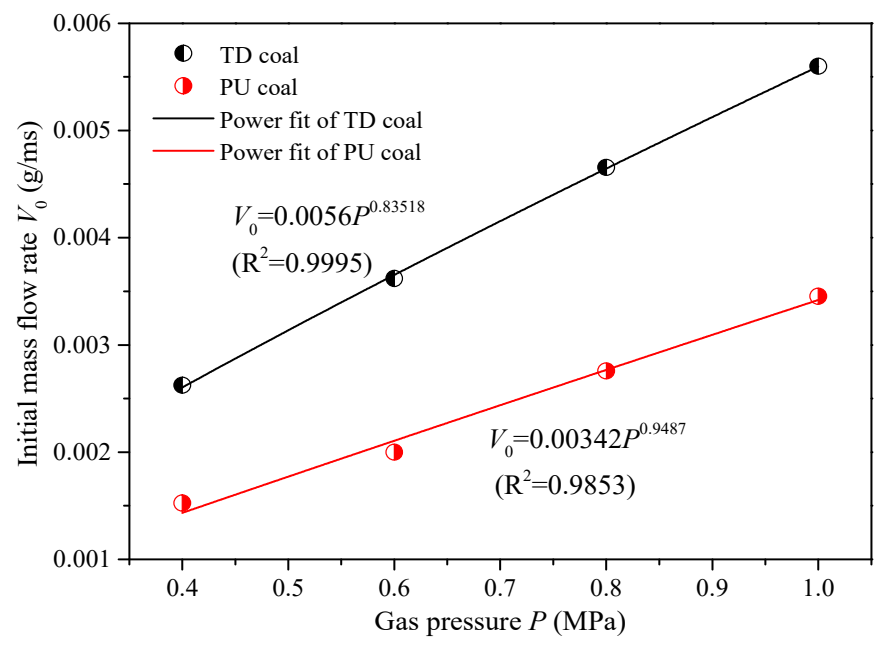

(a) Power fit

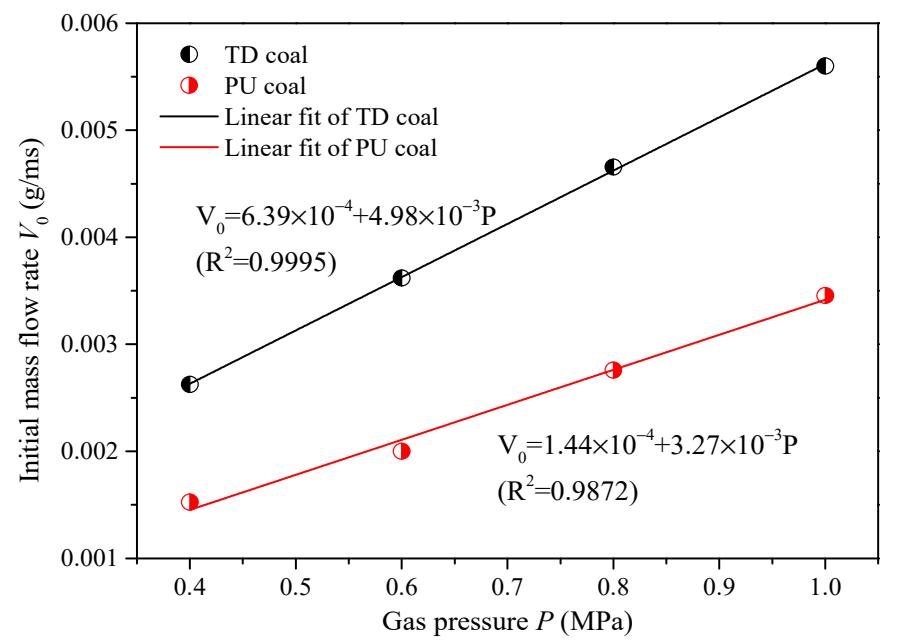

(b) Linear fit

Figure 7. Correlation of the mass flow rate vs. gas pressure at the initial time.

\subsection{Gas Velocity Change}

It is generally believed that the main energy sources come from elastic potential energy exerted by in situ stress and gas energy of the coals during an outburst process. The energy analysis results of the field outburst cases and outburst simulation tests both show that the gas energy is generally about 10-1000 times higher than the elastic potential energy $[7,8,38]$. Jiang et al. [9] considered that the energy of gas expansion in the gas energy is actually the energy leading to the destruction and ejection of coals in the outburst process, analyzing the whole outburst process and its energy dissipation law. The outburst risk of coal seam can be identified by using the initial released expansion energy of gas of the coal mass. The experimental results show that the gas expansion energy released by coals in the first $13 \mathrm{~s}$ is approximately in the proportion of $14-16 \%$ of the gas energy $[7,20,33]$. In the calculation of gas expansion energy, gas velocity is a key parameter, reflecting the dynamic performance of gas desorption to a certain extent, and the gas velocity can be calculated in Figure 1.

The gas velocity at different times during the gas initial desorption is shown in Figure 8 , indicating that it can be divided into four stages in the entire change process. In Stage 1, the gas velocity is greater than the sound velocity, decreasing slowly and linearly with time. After entering Stage 2, the gas velocity decreases rapidly and linearly to approximately $100 \mathrm{~m} / \mathrm{s}$. In Stage 3, the gas velocity begins to decrease. In the end, it almost became stable, close to $5 \mathrm{~m} / \mathrm{s}$ (Stage 4). For the both coal samples, the maximum gas velocity in the entire process is not more than $430 \mathrm{~m} / \mathrm{s}$. Figure 8 shows that for the two coal masses, the gas velocity change rate decreases with increasing gas pressure in Stage 1, because of the congestion effect; while during the later three stages, the increased gas pressure increases the gas velocity. Figure 9 presents a comparison of the change in the gas velocity with time under different gas pressures of the TD and PU coals during the initial gas desorption, indicating that the gas velocity of the TD coal is faster compared to the PU coal bearing the same pressure. The results indicate that the increased gas pressure produces the stronger migration ability of gas flow carrying the broken coal mass after an outburst occurrence, especially for the TD coal $[37,40]$. 

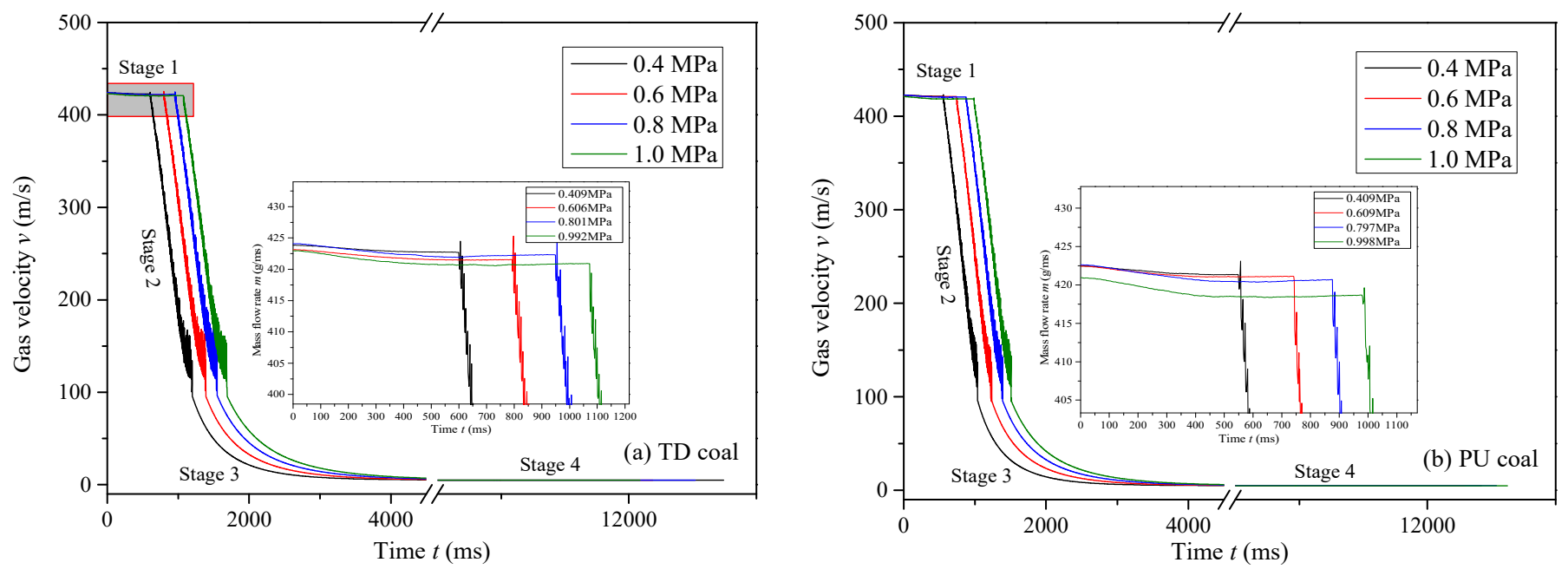

Figure 8. Change curve of gas velocity vs. time under different gas pressures during gas initial desorption of coal particles.
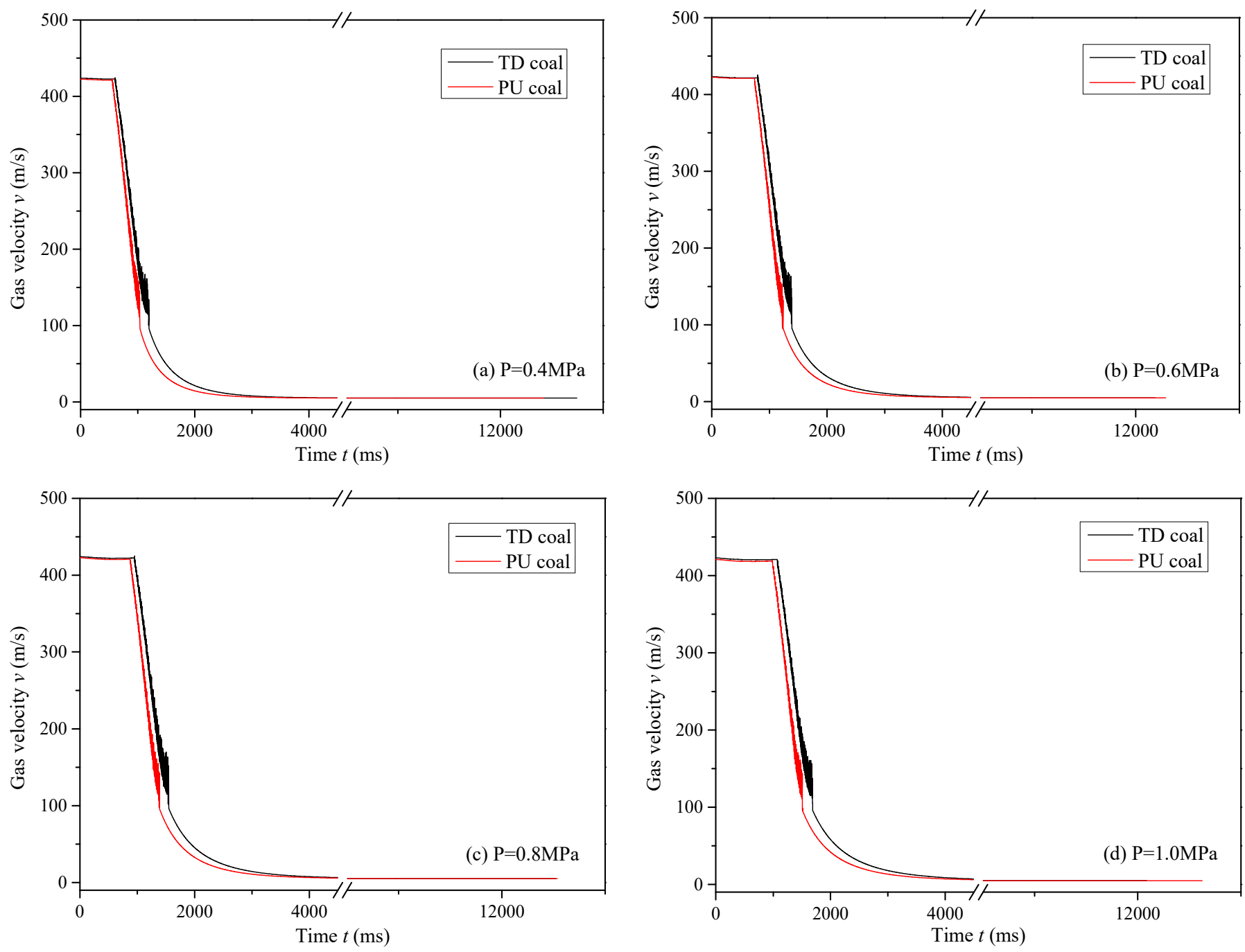

Figure 9. Comparison of gas velocity change vs. time under the same gas pressure between TD coal and PU coal. 


\section{Discussion}

\subsection{Effect of the Characterization of Gas Initial Desorption on an Outburst Occurrence}

An outburst occurs as a kinetic result of coupling and cooperation among multiple parameters. At present, in the related theories of outburst occurrence mechanism, "spherical shell instability" mechanism provides the detailed stage characteristics and the mechanical conditions during an outburst occurrence [9]. This theory has also been validated by many scholars $[26,41,42]$. The outburst process is divided into three stages in this theory, as shown in Figure 10. And the mechanical conditions satisfying equations can be seen from Equations (1)-(3).

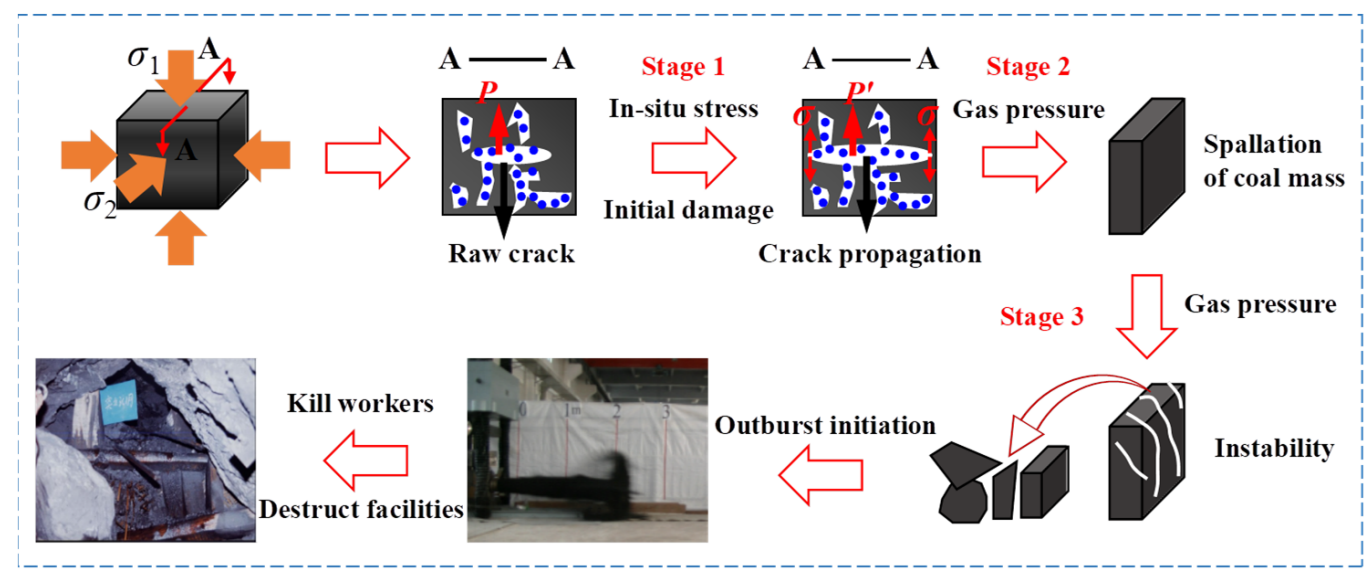

Figure 10. The mechanical process of an outburst initiation.

Stage 1:

$$
\sigma^{\prime \prime} \theta \geq \frac{1+\sin \varphi}{1-\sin \varphi} \sigma_{\mathrm{r}}^{\prime \prime}+\frac{2 f_{\mathrm{c}} \cos \varphi}{1-\sin \varphi}
$$

Stage 2:

$$
p_{i}-p_{0} \geq M \frac{K_{\mathrm{c}} \sqrt{\pi}}{2 \eta \sqrt{r}}
$$

Stage 3:

$$
p^{\prime}-p_{0} \geq\left[1-0.00875\left(\varphi_{\mathrm{i}}-20^{\circ}\right)\right]\left(1-0.000175 \frac{R_{\mathrm{i}}}{t_{\mathrm{i}}}\right)\left(0.3 E \frac{t_{\mathrm{i}}{ }^{2}}{R_{i}{ }^{2}}\right)
$$

Generally, the strength of coal mass can be indirectly reflected by the firmness coefficient, $f$ value (protodyakonov coefficient) in China. The $f$ value is generally less than 0.5 for the coal mass with an outburst risk on site [43]. As the destruction carrier suffered from in situ stress and gas pressure in the outburst process, its strength greatly affects the difficulty level of outburst occurrence. The greater the coal strength, the greater the corresponding cohesion, internal friction angle, and fracture toughness of the coal mass, and the more difficult it is to meet Equation (1) under the same in situ stress. When less cracks are generated, it is more difficult to form the spallation coal mass under the same pressure of gas or to meet the critical conditions required by Equations (2) and (3). Further pulverization of coal mass is also not conducive. To a certain extent, the coal strength determines the critical value of gas pressure and other parameters of outburst occurrence. The actual " 5.15 " outburst accident in 2017 in the Xuehu coal mine also shows that the outburst easily occurred in the TD coal ( $f$ value, 0.28$)$, mainly because the blasting disturbed the TD coal hidden in the PU coal ( $f$ value, 0.88 ).

The three stages proposed by Jiang et al. [8] show that the low strength of TD coal is conducive to the formation of Stage 1, and whether the latter two stages can be carried out smoothly is directly related to the occurrence of an outburst. Figure 3 shows that the pressure gradient of gas formed in TD coal is also higher compared with the PU coal. Therefore, between the two types of coals, Equation (2) is more likely to be met for the 
TD coal with initial failure under the same gas pressure and the same degree of damage, easily leading to the spallation of coal mass. The conditions leading to the instability of spallation coal mass are shown in Equation (3), and an outburst occurrence depends on whether the local gas pressure in the large crack can meet the instability conditions. Figures 6 and 7 indicate that the mass flow rate and initial desorption rate of gas of the TD coal are approximately two times of those of the PU coal mass. The total gas desorption amount of the TD coal is reported to be about twice of the amount of the PU coal with the equal level of gas pressure in the literature [20]. Therefore, after the formation of spallation coal mass in the TD coal, the amount of gas accumulated in the subsequent large cracks increases, increasing the gas pressure, thus easily meeting the conditions required by Equation (3). At the same time, Figures 8 and 9 show that as gas desorption is a kinetic process, and the gas accumulation process in the large cracks at the back of the spallation coal mass also faces rapid impact of gas with impact capacity on the spallation coal mass. According to the momentum theorem in physics, the relationship between the applied force and the quantity of gas and gas velocity satisfies Equation (4). Therefore, the gas velocity desorbing from the TD coal is higher, the greater the desorption amount, the greater the impulse of accumulated gas, the greater the applied force formed on the surface of spallation coal mass, and the more prone the spallation coal mass is to instability and initiating an outburst.

$$
\mathrm{F} t=m_{\mathrm{g}} v
$$

where $\mathrm{F}$ is the applied force $(\mathrm{N}) ; \boldsymbol{t}$ is the action time $(\mathrm{s}) ; \boldsymbol{m}_{\mathrm{g}}$ is the quality of gas $(\mathrm{kg})$; and $v$ is the gas velocity $(\mathrm{m} / \mathrm{s})$.

\subsection{Evolution Law of Gas Expansion Energy}

In Section 4.1, according to the initial desorption characteristics of TD and PU coals, the occurrence of an outburst was analyzed from the mechanical effect. The outburst process can also be regarded as the process of energy accumulation, transfer and release, and gas energy plays a leading role. Moreover, the gas energy participating in the outburst initiation and development process is the gas expansion energy with dynamic effect. In this section, the mechanism of outburst occurrence is further explained in the characterization of gas expansion energy released from the both coals. The gas expansion energy released by the coal mass can be calculated according to Figure 2 .

In order to simplify the analysis, this section only shows the data of gas expansion energy released by the TD coal with time, as shown in Figure 11, indicating that the release process of gas expansion energy with time can be classified as two stages. In each stage, the gas expansion energy first increases and then decreases. There are two peaks in the entire process, and the peak value of \#1 is far less than that of \#2. According to the relevant outburst occurrence mechanism, the coal mass again undergoes destruction during the gas desorption $[7,13]$. Therefore, the gas expansion energy shows two stages, reflecting the redestruction process of gas to coal mass, i.e., after the coal mass is exposed, the free gas is rapidly desorbed because of the pressure gradient; at the same time, with the partial adsorbed gas changing to free gas and with increasing desorption amount, the gas expansion energy begins to increase until the appearance of maximum of peak 1 . Because of the disconnection of the gas migration channels in the coal mass, the free gas transformed from the adsorbed gas accumulates locally, decreasing the gas desorption amount and gas velocity, which in turn decreases the gas expansion energy. With further accumulation of free gas in the pores and fissures, the gas pressure gradient increases, tearing the coal mass, which is also a key reason for the formation of pulverized coals in the outburst process. Massive gas is rapidly released again, leading to the appearance of second peak (\#2). With decreasing amount of adsorbed gas changing into free gas, the corresponding gas pressure gradient decreases, and the released gas expansion energy decreases, eventually ending the initial gas desorption process of coal. In addition, the figure shows that as the increased gas pressure will release more free gas and adsorbed gas in the coal mass, the longer the two stages of gas expansion energy release last. However, 
the gas expansion energy from the coals is almost released within about 1.5-2 $\mathrm{s}$. This shows that although an outburst process comprises several subcycles, each subcycle only lasts for less than $2 \mathrm{~s}$. If the process of an outburst can be divided into 10 subcycles, then the entire outburst process only lasts about $20 \mathrm{~s}$, explaining that the average duration of a typical outburst accident is $\sim 20 \mathrm{~s}$ [6].
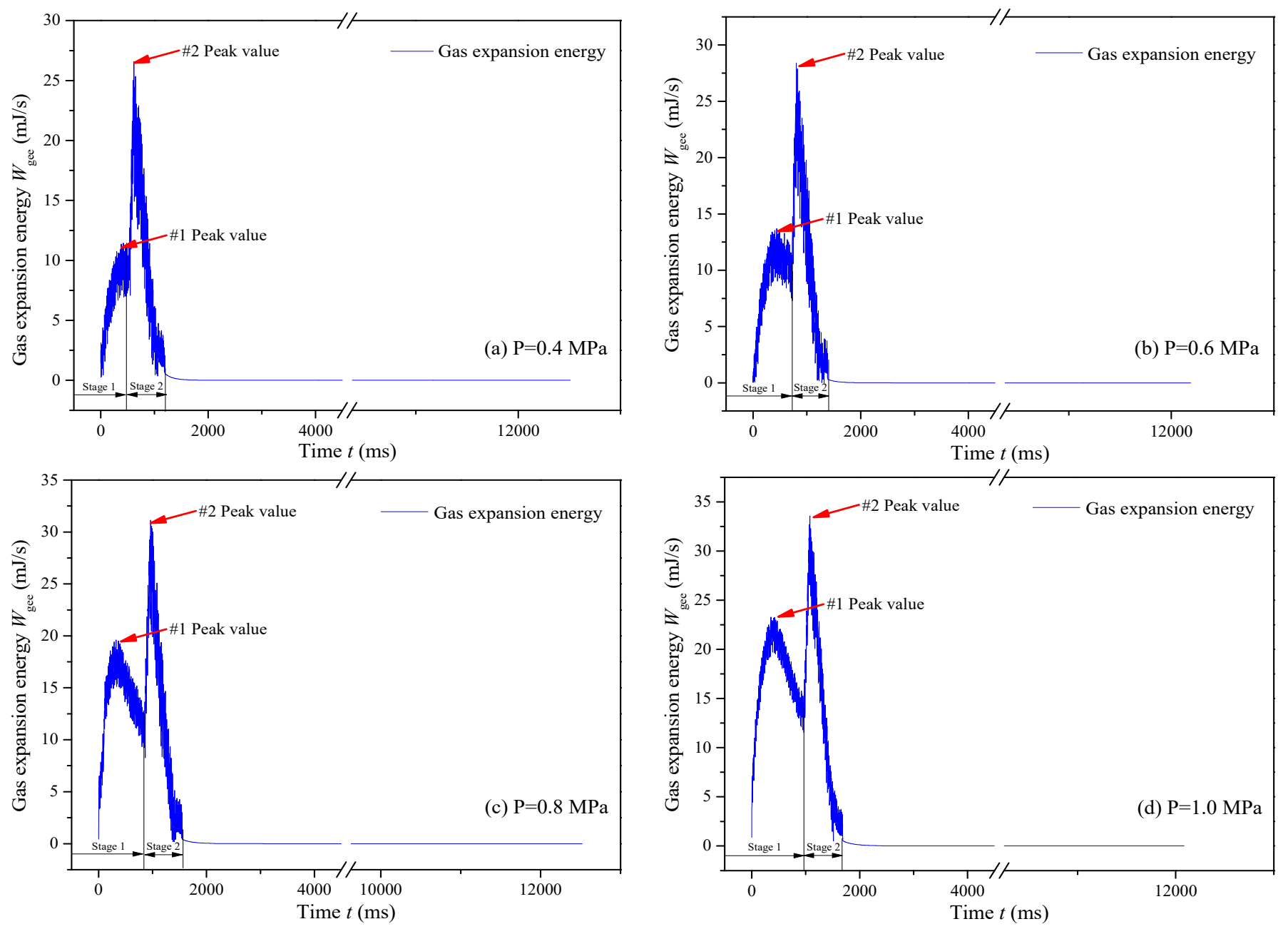

Figure 11. Released process of gas expansion energy from the TD coals with time.

In order to further compare and analyze the characterization difference of the released gas expansion energy between the TD and PU coals, as well as the influence mechanism of gas pressure, the change in the two peak values of the two coals with gas pressure is shown in Figure 12, indicating that for PU coal mass the peak values of the TD coal is about 2-3 times of its irrespective of the peak value of \#1 or \#2. The relationship between the two peak values and gas pressure can be expressed by linear function. The positive correlation between the peak value and gas pressure also confirmed that increased gas pressure leads to more serious damage to the coal mass, which produces greater released gas expansion energy, and then it is the more prone to initiate an outburst. In addition, Figure 3 also demonstrates that the gas desorption produces a high gas pressure gradient near the exposed surface, forming tensile stress exerting to the surface of spallation coal mass. The tensile stress is increased by the increased pressure, and the spallation coal mass is more easily and seriously damaged, resulting in the ejection phenomenon of the small coal blocks and pulverized coals as mentioned in the literature [44,45]. 


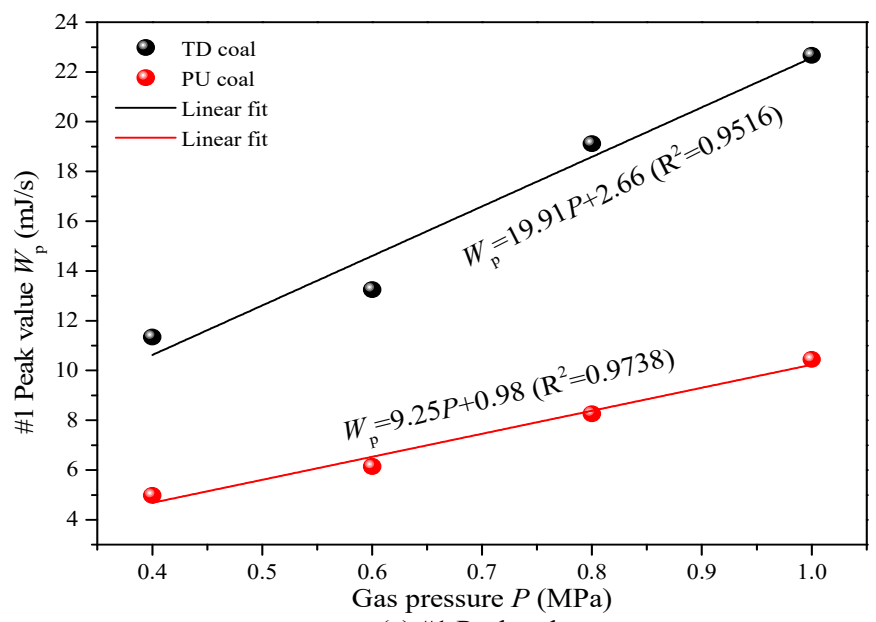

(a) \#1 Peak value

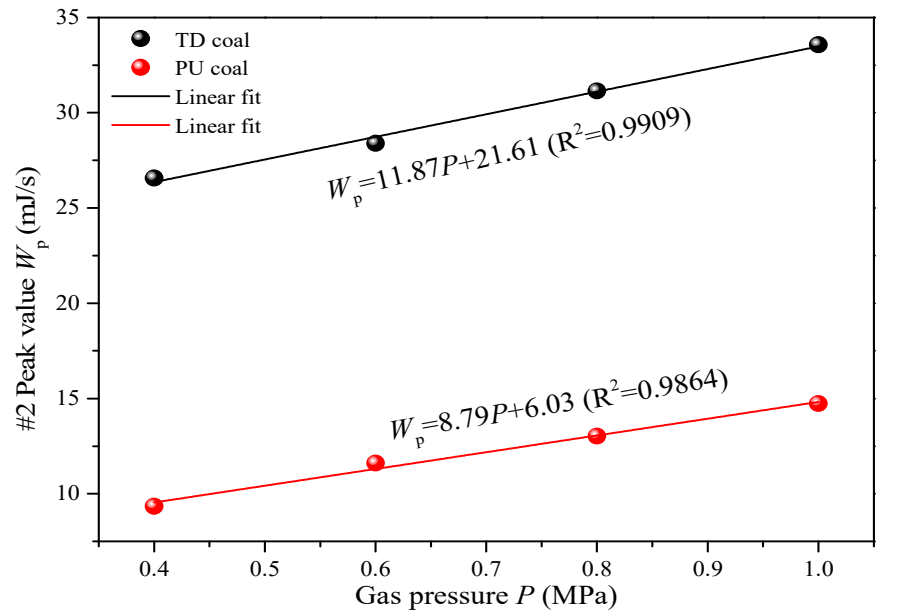

(b) \#2 Peak value

Figure 12. Relationship between the peak value of gas expansion energy and gas pressure.

It can be concluded that the evolution law of gas expansion energy can reflect the outburst process. Jiang et al. [9] found that the total gas expansion energy (TGEE) released in the initial desorption process of coals is closely related to the risk level of coal and gas outburst and concluded that when the TGEE released by coals is greater than $42.98 \mathrm{~mJ} / \mathrm{g}$, the coal mass will have outburst risk. The critical conditions of outburst risk of different coals is shown in Figure 13. The relationship between the TGEE and gas pressure can be expressed by a linear function. It can be seen from the figure that under the same gas pressure level, the TGEE released by TD coal is far greater than that released by PU coal. Meanwhile, the greater the gas pressure, the bigger the difference. When the gas pressure exceeds $0.31 \mathrm{MPa}$, the TD coal has outburst risk. When the gas pressure is $1.02 \mathrm{MPa}$, the TD coal has outburst risk. It also shows that compared with PU coal, TD coal is more prone to instability and failure and then initiates an outburst due to its low mechanical strength and high dynamic intensity in the process of gas desorption. Therefore, it is the key to accurately determine the TGEE released by TD coal when determining the outburst risk of coal seam. At the same time, the critical values of outburst risk of coal masses are greatly different, because of the coal masses with different mechanical strengths developed in the coal seam. Therefore, the critical values of outburst risk of corresponding coal masses in a coal seam should be determined respectively, which can effectively conduct the prevention and control of outburst risk by the disaster sources, disaster intensities at the level of space-time.

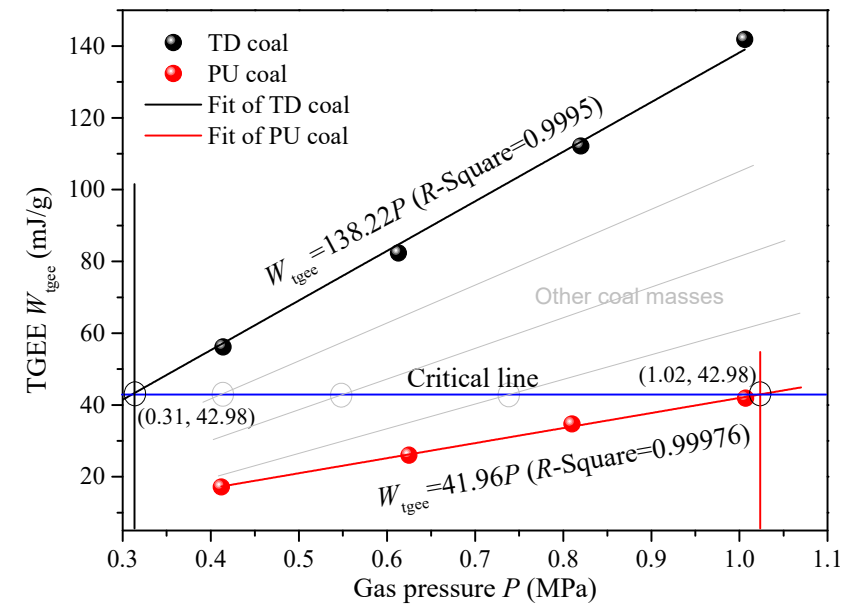

Figure 13. The critical conditions of outburst risk of different coals. 


\section{Conclusions}

In order to further improve the understanding of an outburst occurrence mechanism, the dynamic characterization of the key parameters in the process of gas initial desorption are revealed by taking the gas desorption law of the tectonically deformed and primaryundeformed coal masses as the breakthrough point. The experimental results provide the understanding of an outburst occurrence mechanism, leading to the following conclusions.

(1) Increased gas pressure leads to higher pressure gradient when gas is initially desorbed, and the gas pressure gradient formed on the surface of the tectonically deformed coal is greater. The temperature change rates (falling rate and rising rate) of the coal mass increase, and the minimum and final stable temperatures decrease with increased pressure, in which these two values of the tectonically deformed coal are generally less than the corresponding temperatures of the primary-undeformed coal. The minimum and the final stable temperatures of the coal mass are linearly related to gas pressure.

(2) Increased gas pressure produces larger mass flow rate, and the time required from rapid reduction stage to stable stage is longer. The mass flow rate at different times of the tectonically deformed coal is faster compared with the primary-undeformed coal. The correlation of the mass flow rate at the initial time of the tectonically deformed coal and gas pressure can be expressed by power function or linear function, while the relationship of the PU coal can be better expressed by a linear function. In addition, whether it is a power function or a linear function, the gas pressure has a greater effect on the mass flow rate at the initial time of the primary-undeformed coal.

(3) The gas velocity in the initial desorption process has four stages. For the two types of coals, the increased gas pressure decreases the gas velocity during the desorption in Stage 1 due to the congestion effect; in the later three stages, increased gas pressure generates the higher gas velocity. The gas velocity of the tectonically deformed coal is higher than that of the primary-undeformed coal bearing the same gas pressure. The increased gas velocity and the desorption quantity increase the impulse intensity formed by the accumulated gas, and the greater the applied force formed on the surface of the spallation coal mass, making the spallation coal mass more prone to instability and initiating an outburst.

(4) The release process of gas expansion energy vs. time has two stages. In each stage, the released gas expansion energy first increased and then decreased. There are two peaks in the entire process, and the peak value of \#1 is far less than that of \#2. By increasing the gas pressure, the duration of the two stages of gas expansion energy release is longer. Whether it is the peak value of $\# 1$ or \# 2, the corresponding released gas expansion energy of the tectonically deformed coal is about 2-3 times of that of the primary-undeformed coal mass. Furthermore, under the same gas pressure level, the total gas expansion energy released by the tectonically deformed coal is far greater than that released by the primary-undeformed coal. The positive correlations among the peak values, the total values of gas expansion energy and gas pressure also confirmed that increased gas pressure seriously damages the coal mass, releasing greater amount of gas expansion energy and is more prone to initiating an outburst.

Author Contributions: Conceptualization, C.W.; methodology, C.W. and X.L.; data curation, C.W. and Y.C.; validation, C.X. and Z.T.; formal analysis, C.Z. and Y.D.; resources, X.G. and C.J. All authors have read and agreed to the published version of the manuscript.

Funding: This research was funded by the China Postdoctoral Science Foundation, grant number 2020M672177, the Second Batch of Postdoctoral Application Projects of Qingdao in 2019, grant number qdyy20190084, the Fundamental Research Funds for the Central Universities, grant number 20CX06050A, the National Natural Science Foundation of China, grant number 41802188, and in part by the National Key Research and Development Plan, grant number 2017 YC0804503.

Data Availability Statement: The data presented in this study are available on request from the corresponding author. The data are not publicly available due to the original data is used in a complex process. 
Acknowledgments: The authors would like to thank the editors and anonymous reviewers for their careful review on the paper. Meanwhile, We are sincerely grateful to our motherland, the People's Republic of China, for her powerful support.

Conflicts of Interest: The authors declare no conflict of interest.

\section{Nomenclature List}

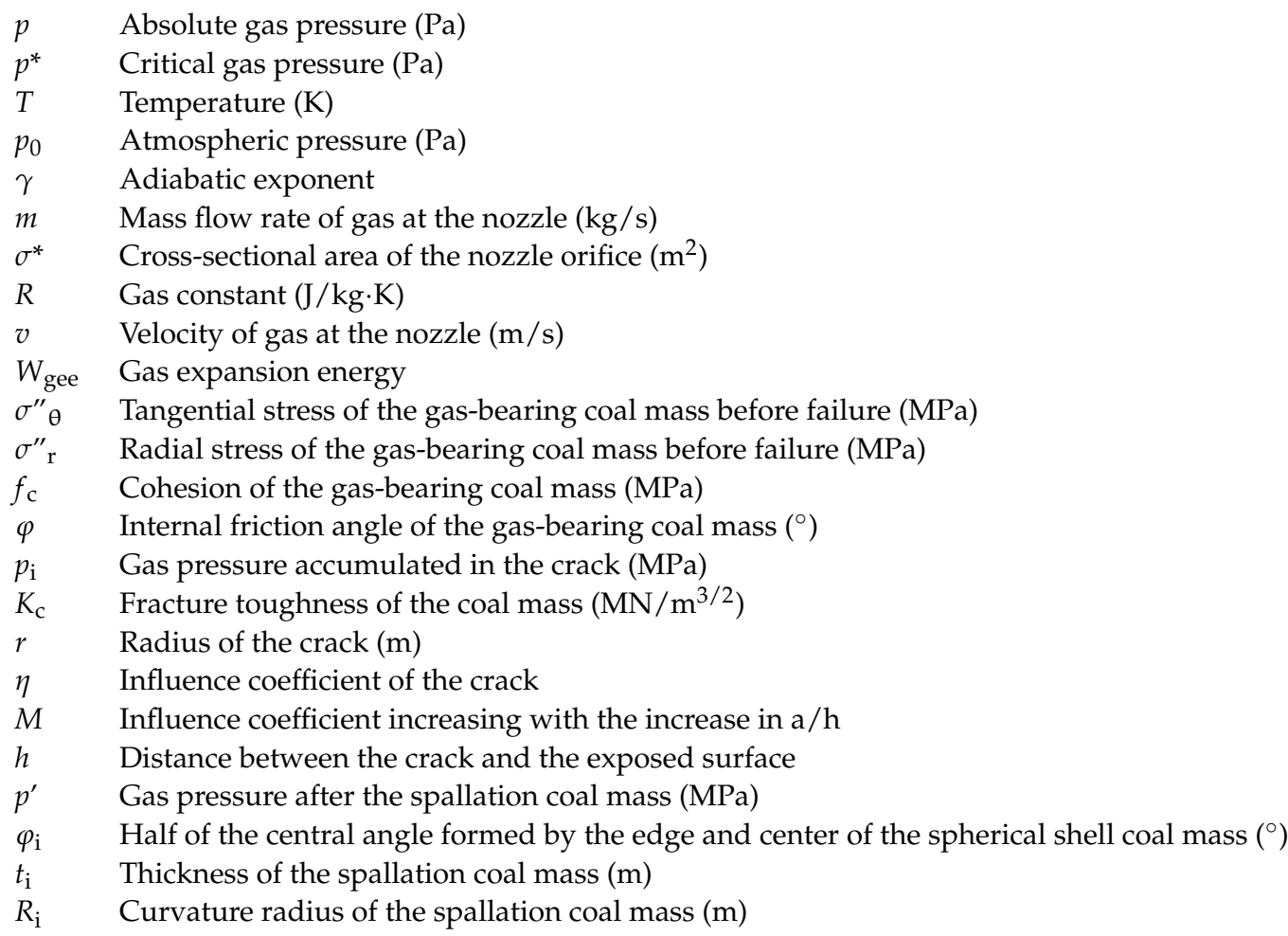

\section{References}

1. Kang, Y.L.; Huang, F.S.; You, L.J.; Li, X.C.; Gao, B. Impact of fracturing fluid on multi-scale mass transport in coalbed methane reservoirs. Int. J. Coal Geol. 2016, 154-155, 123-135. [CrossRef]

2. Yan, X.L.; Zhang, S.H.; Tang, S.H.; Li, Z.C.; Yi, Y.X.; Zhang, Q.; Hu, Q.P.; Liu, Y.X. A comprehensive coal reservoir classifification method base on permeability dynamic change and its application. Energies 2020, 13, 644. [CrossRef]

3. Liu, Y.W.; Wang, D.D.; Hao, F.C.; Liu, M.J.; Mitri, H.S. Constitutive model for methane desorption and diffusion based on pore structure differences between soft and hard coal. Int. J. Min. Sci. Technol. 2017, 27, 937-944. [CrossRef]

4. Liu, P.; Qin, Y.P.; Liu, S.M.; Hao, Y.J. Non-linear gas desorption and transport behavior in coal matrix: Experiments and numerical modeling. Fuel 2018, 214, 1-13. [CrossRef]

5. Li, X.B.; Li, Y.B.; Tang, J.T. Determining the initial stage loss content of TD coal gas desorption via the Bayesian probability method. Nat. Hazards 2019, 97, 83-97. [CrossRef]

6. Wei, F.Q.; Shi, G.S.; Zhang, T.G. Study on coal and gas outburst prediction indexes base on gas expansion energy. J. China Coal Soc. 2010, 35, 95-99.

7. Wang, C.J.; Yang, S.Q.; Yang, D.D.; Li, X.W.; Jiang, C.L. Experimental analysis of the intensity and evolution of coal and gas outbursts. Fuel 2018, 226, 252-262. [CrossRef]

8. Valliappan, S.; Zhang, W.H. Role of gas energy during coal outbursts. Int. J. Numer. Methods Eng. 1999, 44, 875-895. [CrossRef]

9. Jiang, C.L.; Xu, L.H.; Li, X.W.; Tang, J.; Chen, Y.J.; Tian, S.X.; Liu, H.H. Identifification Model and Indicator of Outburst-Prone Coal Seams. Rock Mech. Rock Eng. 2015, 48, 409-415. [CrossRef]

10. Wang, Z.F.; Sun, R.; Qi, L.L.; Liu, J. Theoretical equation of gas desorption of particle coal under the non-uniform pressure condition and its analytical solution. Saf. Sci. 2012, 50, 861-864. [CrossRef]

11. Xu, L.H.; Jiang, C.L.; Tian, S.X. Experimental study of the gas concentration boundary condition for diffusion through the coal particle. J. Nat. Gas Sci. Eng. 2014, 21, 451-455. [CrossRef]

12. Yang, T.; Chen, P.; Li, B.; Nie, B.S.; Zhu, C.J.; Ye, Q.S. Potential safety evaluation method based on temperature variation during gas adsorption and desorption on coal surface. Saf. Sci. 2019, 113, 336-344. [CrossRef] 
13. Jin, K.; Cheng, Y.P.; Ren, T.; Zhao, W.; Tu, Q.Y.; Dong, J.; Wang, A.Y.; Hu, B. Experimental investigation on the formation and transport mechanism of outburst coal-gas flow: Implications for the role of gas desorption in the development stage of outburst. Int. J. Coal Geol. 2018, 194, 45-58. [CrossRef]

14. Zhao, W.; Wang, K.; Cheng, Y.P.; Liu, S.M.; Fan, L. Evolution of gas transport pattern with the variation of coal particle size: Kinetic model and experiments. Powder Technol. 2020, 367, 336-346. [CrossRef]

15. Davarpanah, A.; Mirshekari, B. Experimental investigation and mathematical modeling of gas diffusivity by carbon dioxide and methane kinetic adsorption. Ind. Eng. Chem. Res. 2019, 58, 12392-12400. [CrossRef]

16. Wen, Z.H.; Wei, J.P.; Wang, D.K.; Wang, C. Experimental Study of Gas Desorption Law of Deformed Coal. Procedia Eng. 2011, 26, 1083-1088. [CrossRef]

17. Ju, Y.W.; Li, X.S. New research progress on the ultrastructure of tectonically deformed coals. Prog. Nat. Sci. 2009, 19, 1455-1466. [CrossRef]

18. Li, W.; Jiang, B.; Moore, T.A.; Wang, F.; Liu, J.G.; Song, Y. Characterization of the chemical structure of tectonically deformed coals. Energy Fuels 2017, 31, 6977-6985. [CrossRef]

19. Chen, Y.L.; Qin, Y.; Li, Z.P.; Shi, Q.M.; Wei, C.T.; Wu, C.F.; Qu, Z.H. Differences in desorption rate and composition of desorbed gases between undeformed and mylonitic coals in the Zhina Coalfield, Southwest China. Fuel 2019, 239, 905-916. [CrossRef]

20. Wang, C.J.; Yang, S.Q.; Li, X.W.; Li, J.H.; Jiang, C.L. Comparison of the gas initial desorption and gas-release energy characteristics from tectonically-deformed and primary-undeformed coal. Fuel 2019, 238, 66-74. [CrossRef]

21. Liu, X.F.; Song, D.Z.; He, X.Q.; Nie, B.S.; Wang, L.K. Insight into the macromolecular structural difffferences between hard coal and deformed soft coal. Fuel 2019, 245, 188-197. [CrossRef]

22. Fu, X.; Wang, K.J.; Yang, T.H. Gas irradiation feature of tectonic coal. J. China Coal Soc. 2008, 33, 775-779.

23. Li, Y.B.; Zhang, Y.G.; Zhang, Z.M.; Jiang, B. Experimental study on gas desorption of tectonic coal at initial stage. J. China Coal Soc. 2013, 38, 15-20.

24. Yang, Y.; Liu, S.M. Estimation and modeling of pressure-dependent gas diffusion coefficient for coal: A fractal theory-based approach. Fuel 2019, 253, 588-606. [CrossRef]

25. Xie, G.X.; Yin, Z.Q.; Wang, L.; Hu, Z.X.; Zhu, C.Q. Effects of Gas Pressure on the Failure Characteristics of Coal. Rock Mech. Rock Eng. 2017, 50, 1711-1723. [CrossRef]

26. Cao, W.Z.; Shi, J.Q.; Durucan, S.; Si, G.Y.; Korre, A. Gas-driven rapid fracture propagation under unloading conditions in coal and gas outbursts. Int. J. Rock Mech. Min. Sci. 2020, 130, 104325. [CrossRef]

27. Hu, X.; Xie, J.; Cai, W.C.; Wang, R.; Davarpanah, A. Thermodynamic effects of cycling carbon dioxide injectivity in shale reservoirs. J. Pet. Sci. Eng. 2020, 195, 107717. [CrossRef]

28. Nabavi, M.; Elveny, M.; Danshina, S.D.; Behroyan, I.; Babanezhad, M. Velocity prediction of Cu/water nanofluid convective flow in a circular tube: Learning CFD data by differential evolution algorithm based fuzzy inference system (DEFIS). Int. Commun. Heat Mass Transf. 2021, 126, 105373. [CrossRef]

29. Wu, S.; Tang, D.Z.; Li, S.; Chen, H.; Wu, H.Y. Coalbed methane adsorption behavior and its energy variation features under supercritical pressure and temperature conditions. J. Pet. Sci. Eng. 2016, 146, 726-734. [CrossRef]

30. Yue, G.W.; Zeng, C.L.; Huo, L.P.; Zheng, X.J. Measurement and modeling of temperature evolution during methane desorption in coal. Sci. Rep. 2020, 10, 3146.

31. Lama, R.D.; Bodziony, J. Management of outburst in underground coal mines. Int. J. Coal Geol. 1998, 35, 83-115. [CrossRef]

32. Yang, D.D.; Chen, Y.J.; Tang, J.; Li, X.W.; Jiang, C.L.; Wang, C.J.; Zhang, C.J. Experimental research into the relationship between gas initial release and coal-gas outbursts. J. Nat. Gas Sci. Eng. 2018, 50, 157-165. [CrossRef]

33. Wang, C.J.; Yang, S.Q.; Li, J.H.; Li, X.W.; Jiang, C.L. Influence of coal moisture on gas initial desorption and gas-release energy characteristics. Fuel 2018, 232, 351-361. [CrossRef]

34. Xu, L.H.; Jiang, C.L. Initial desorption characterization of methane and carbon dioxide in coal and its inflfluence on coal and gas outburst risk. Fuel 2017, 203, 700-706. [CrossRef]

35. Chen, Y.J.; Yang, D.D.; Tang, J.; Li, X.W.; Jiang, C.L. Determination method of gas initial desorption law of coal based on flow characteristics of convergent nozzle. J. Loss Prev. Process Ind. 2018, 54, 222-228. [CrossRef]

36. Liang, Y.P.; Wang, F.K.; Li, X.L.; Jiang, C.L.; Li, L.; Chen, Y.L. Study on the influence factors of the initial expansion energy of released gas. Process Saf. Environ. Prot. 2018, 117, 582-592. [CrossRef]

37. Otuonye, F.; Sheng, J.A. numerical simulation of gas flow during coal/gas outbursts. Geotech. Geol. Eng. 1994, 12, 15-34. [CrossRef]

38. Jiang, C.L.; Yu, Q.X. The Spherical Shell Instability Mechanism and Prevention Technology of Coal and Gas Outburst; China University of Mining and Technology Press: Xuzhou, China, 1998.

39. Sobczyk, J. The inflfluence of sorption processes on gas stresses leading to the coal and gas outburst in the laboratory conditions. Fuel 2014, 90, 1018-1023. [CrossRef]

40. Sun, D.L.; Hu, Q.T.; Miao, F.T. A mathematical model of coal-gas flow conveying in the process of coal and gas outburst and its application. Procedia Eng. 2011, 26, 147-153.

41. Xu, T.; Tang, C.A.; Yang, T.H.; Zhu, W.C.; Liu, J. Numerical investigation of coal and gas outbursts in underground collieries. Int. J. Rock Mech. Min. Sci. 2006, 43, 905-919. [CrossRef] 
42. Tu, Q.Y.; Cheng, Y.P.; Liu, Q.Q.; Guo, P.K.; Wang, L.; Li, W.; Jiang, J.Y. Investigation of the formation mechanism of coal spallation through the cross-coupling relations of multiple physical processes. Int. J. Rock Mech. Min. Sci. 2018, 105, 133-144. [CrossRef]

43. China's State Administration of Work Safety (CSAWS). Provisions on Prevention of Coal and Gas Outburst; Coal Industry Press: Beijing, China, 2009.

44. Guan, P.; Wang, H.Y.; Zhang, Y.X. Mechanism of instantaneous coal outbursts. Geology 2009, 37, 915-918. [CrossRef]

45. Wang, S.G.; Elsworth, D.; Liu, J.S. Rapid decompression and desorption induced energetic failure in coal. J. Rock Mech. Geotech. Eng. 2015, 7, 345-350. [CrossRef] 